\title{
CLINICAL OUTCOME OF LAPAROSCOPIC SUBTOTAL CHOLECYSTECTOMY IN THE TREATMENT OF COMPLICATED CHOLECYSTITIS
}

\author{
Varun Gupta1, Vinay Karwal2, Sanjeev Kumar Singla ${ }^{3}$, Manvi Gupta $^{4}$ \\ ${ }_{1}^{1}$ Associate Professor, Department of Surgery, DMC and H, Ludhiana, Punjab. \\ 2Junior Resident, Department of Surgery, DMC and H, Ludhiana, Punjab. \\ 3 Professor, Department of Surgery, DMC and H, Ludhiana, Punjab. \\ ${ }^{4}$ Consultant Pathologist, ESIC, Model Hospital, Ludhiana, Punjab.
}

\begin{abstract}
BACKGROUND

Laparoscopic cholecystectomy has replaced open cholecystectomy as the surgical procedure of choice for symptomatic gallstones. The presence of risk factors such as difficult Calot's triangle, various liver pathologies like hard fibrotic liver tissue as seen in chronic cholecystitis, severe adhesions between the liver and gallbladder wall, oedematous tissue in severe acute cholecystitis and neovascularity as in cirrhotic liver make the dissection very difficult and dangerous.

The present study was conducted to evaluate the role and outcome of laparoscopic subtotal cholecystectomy in the treatment of complicated cholecystitis.
\end{abstract}

\section{MATERIALS AND METHODS}

This was a descriptive study conducted on all patients who underwent laparoscopic subtotal cholecystectomy at Dayanand Medical College, Ludhiana from 1st January 2014 to 30th June 2017. Details of the patients were retrieved and analysed for demographic data, history and clinical findings, investigations, operative findings, length of hospital stay, complications and outcome.

\section{RESULTS}

The total number of laparoscopic cholecytectomies done during the total duration of the study was 1,926 . The overall incidence of laparoscopic subtotal cholecystectomy in our study was $1.1 \%$.

\section{CONCLUSION}

Laparoscopic subtotal cholecystectomy may be a safe alternative to open subtotal cholecystectomy in patients with various forms of complicated cholecystitis. If difficulty is encountered when dissecting the neck and Calot's triangle, isolating the cystic duct is unnecessary and the conversion rate decreases by devising alternate methods for handling hostile Calot's triangle as described in this study. This study demonstrates that laparoscopic subtotal cholecystectomy is associated with a reduced risk of severe complications in the patients with complicated cholecystitis.

\section{KEY WORDS}

Laparoscopic Subtotal Cholecystectomy, Complicated Cholecystitis. HOW TO CITE THIS ARTICLE: Gupta V, Karwal V, Singla SK, et al. Clinical outcome of laparoscopic subtotal cholecystectomy in the treatment of complicated cholecystitis. J. Evolution Med. Dent. Sci. 2018;7(21):2534-2538, DOI: 10.14260/jemds/2018/570

\section{BACKGROUND}

In 1985 Prof. Dr Erich Mühe of Germany performed the first laparoscopic cholecystectomy.[1] Since its introduction, laparoscopic cholecystectomy has replaced open cholecystectomy as the surgical procedure of choice for symptomatic gallstones.[2] Complicated gallbladder pathologies like chronically inflamed gallbladder, gangrenous gallbladder and empyema gallbladder can make dissection around the Calot's triangle difficult with high risk of injury to common bile duct and hepatic artery or its branches.[3] Such cases are more often used to be converted to open procedure, because when the critical view of safety cannot be obtained during dissection of Calot's triangle, conversion to open surgery is advocated to prevent bile duct injury. [4] However,

'Financial or Other Competing Interest': None.

Submission 03-04-2018, Peer Review 04-05-2018,

Acceptance 11-05-2018, Published 21-05-2018.

Corresponding Author:

Dr. Manvi Gupta,

\#28-B, Tagore Nagar,

Opposite Hero DMC Heart Institute,

Ludhiana-141001, Punjab.

E-mail: guptamanvi81@yahoo.com

DOI: $10.14260 /$ jemds $/ 2018 / 570$

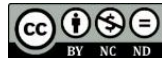

this may result in increased post-operative pain, delayed mobility, prolonged hospitalisation, adhesion formation and incisional hernia formation. In addition, conversion does not necessarily improve exposure or facilitate cystic duct identification. ${ }^{[5]}$ Thus, experienced laparoscopic surgeons feel comfortable proceeding laparoscopically using alternative approaches and techniques such as cholecystostomy, fundusfirst approach and subtotal cholecystectomies to decrease the risks related to difficult gallbladder.[6,7] Subtotal cholecystectomy leaves some portion of the gallbladder when the structures of the Calot triangle cannot be identified and the critical view of safety cannot be achieved. Increasing laparoscopic experience and techniques have made laparoscopic subtotal cholecystectomy a feasible option and a safe alternative as compared to open surgery in difficult cases.[8] However, its indications, feasibility, benefits and technical characteristics are less well documented, therefore this study has been undertaken to evaluate whether laparoscopic subtotal cholecystectomy predisposes to a high or low risk of complications, its safety, effectiveness, postoperative hospital stay and mortality in the management of acute or chronic cholecystitis and its complications like gangrenous, perforated, fibrotic and empyema of the gallbladder. 


\section{MATERIALS AND METHODS}

This study was conducted as a descriptive study in which all patients who underwent laparoscopic subtotal cholecystectomy in Dayanand Medical College, Ludhiana from 1st January 2014 to 30th June 2017 were included. Total 21 patients were enrolled in the study using the following criteria:

\section{Inclusion Criteria}

Patients admitted in Dayanand Medical College, Ludhiana who underwent laparoscopic subtotal cholecystectomy.

\section{Exclusion Criteria}

- Pregnancy.

- Major bleeding disorder.

- Patient not fit for general anaesthesia.

Details of the patients were retrieved and analysed for demographic data like history, clinical findings, investigations, operative findings, length of hospital stay, complications and outcome.

\section{Surgical Technique}

All our patients were operated under general anaesthesia and prophylactic dose of second-generation cephalosporin was given at the time of induction. Pneumoperitoneum was created by standard technique using a Veress needle through a supraumbilical incision. A 10 -mm port was inserted and a $30^{\circ}, 10 \mathrm{~mm}$ camera was used. The other three ports were inserted under complete visualisation after infiltration of the peritoneum with local anaesthetic at the port site. The 1st $5 \mathrm{~mm}$ port was placed along the right anterior axillary line between the 12th rib and the iliac crest. A 2 nd $5 \mathrm{~mm}$ port was inserted in the right subcostal area in the midclavicular line. Another $10 \mathrm{~mm}$ working port was inserted in the epigastrium. The standard laparoscopic approach was tried at first. After division of adhesions of the omentum, stomach, duodenum or colon to the anterior surface of the gallbladder. Dissection of the Calot's triangle was commenced using a diathermy mounted on a Maryland grasper. When we encountered a frozen Calot's triangle then further dissection in Calot's area was stopped, as we felt that further dissection was hazardous because of anatomical uncertainty. A decision to perform laparoscopic subtotal cholecystectomy was taken at surgery in all patients due to obscured Calot's triangle anatomy. During laparoscopic subtotal cholecystectomy, gallbladder neck was managed by different techniques. Endoloop (12), endosuturing of stump (6) and ligation of neck of gallbladder (3). Endoloop placement was the preferred method wherever possible. The gallbladder was opened at the infundibulum away from the Calot's triangle using a diathermy mounted on hook. Suction and irrigation of the opened gall bladder was done and any stones present were removed. Attention was given to avoid stone spillage. The fundus was pulled caudally using the medial grasping forceps and a counter traction achieved by pushing the liver cranially using the lateral grasping forceps. Dissection was done between the liver and the gallbladder starting at the fundus of the gallbladder and proceeding towards the neck of gallbladder as far as possible. 1/0 PDS Endoloop was passed over the gallbladder and tied at the level of the neck of gallbladder. Gallbladder was excised at this level. In cases where endoloop placement was not possible, continuous suturing of the stump was performed using Vicryl 2/0 suture in single layer. In few of the cases where stone was not impacted at the neck of gallbladder and dissection of gallbladder was possible from the liver bed, opening of the gallbladder was not felt necessary. We performed this procedure by creating a plane between the posterior wall of gallbladder and the liver bed, at the neck of gallbladder on the medial aspect. The gall bladder was grasped from its middle part and the stones were gradually milked from the neck towards the fundus of gallbladder using a non-crushing grasper. Gradually, this plane was developed in a medial to lateral direction till a clear plane was developed between the posterior wall of gallbladder and liver bed circumferentially. A 1/0 silk suture was passed in this plane and tied with laparoscopic knot tying technique, ligating the neck of the gallbladder. The gallbladder was incised and divided circumferentially leaving behind the small rim of gallbladder at the level of neck of gallbladder. Dissection between the liver and the gall bladder was commenced and gallbladder was separated from the liver bed.

When it was difficult to find a plane of dissection between the gallbladder and liver bed, excision of gallbladder was done by electrocoagulation using the hook dissector or scissors, at the level of gallbladder junction with the liver bed leaving behind the posterior wall of gallbladder attached to the liver bed with ablation of its mucosa by electrocautery probe. Gallbladder was extracted from the epigastric port using a sterile plastic bag. Careful haemostasis of the liver bed was done. Suction of the subhepatic space and subdiaphragmatic spaces were performed. 28'F drainage tube was placed in the subhepatic region and brought out through the port in anterior axillary line. Inspection of the port site was performed from inside before removal to check for haemostasis and all ports were removed under vision. Fascial defects were closed using $2 / 0$ vicryl. Skin was closed using 2/0 nylon.

All the intraoperative findings and events were noted, duration of the procedure, post-operative complications if any and length of post-operative hospital stay were recorded. Post-operative endoscopic retrograde cholangiopancreatography was carried out selectively if there was prolonged biliary leakage. A post-operative histopathological study was performed on every gallbladder removed. All patients received standard post-operative care and follow-up. Drain was removed once the output was less than $50 \mathrm{~mL} / 24 \mathrm{hrs}$. The data was compiled, and results drawn were compared with National and International literature.

\section{Statistical Analysis}

Statistical analysis was carried out using SPSS. Data collected was described in terms of range, mean \pm standard deviation, frequency (Number of cases) and relative frequency (Percentage) as appropriate.

\section{RESULTS}

Age of patients in our study ranged from 28 years to 70 years. The mean age of patients was $54.86 \pm 11.150$ years. Out of 21 cases, $10(47.6 \%)$ were females and $11(52.4 \%)$ were males. Male: Female ratio was approximately 1: 1. Various comorbidities and investigative findings are depicted in Table 1 and 2 respectively. 


\begin{tabular}{|c|c|c|}
\hline Co-morbidity & No. of Patients & Percentage \\
\hline Diabetes mellitus & 9 & $42.9 \%$ \\
\hline Hypertension & 7 & $33.3 \%$ \\
\hline Coronary artery disease & 3 & $14.3 \%$ \\
\hline CLD-Portal hypertension & 3 & $14.3 \%$ \\
\hline $\begin{array}{c}\text { Attempted laparoscopic } \\
\text { cholecystectomy }\end{array}$ & 1 & $4.8 \%$ \\
\hline \multicolumn{2}{|c|}{ Table 1. Co-Morbidity distribution of Patients } \\
\hline
\end{tabular}

\begin{tabular}{|c|c|c|}
\hline \multicolumn{3}{|c|}{ Alkaline Phosphatase Level Distribution } \\
\hline ALP (IU/L) & No. of Patients & Percentage \\
\hline Less than 150 & \begin{tabular}{|l|l}
15 &
\end{tabular} & $71.4 \%$ \\
\hline $150-300$ & 1 & $4.8 \%$ \\
\hline More than 150 & \begin{tabular}{|l|l}
5 &
\end{tabular} & $23.8 \%$ \\
\hline \multicolumn{3}{|c|}{ Ultrasonography Findings Distribution } \\
\hline Findings & No. of Patients & Percentage \\
\hline Single calculus & \begin{tabular}{l|l}
16 \\
\end{tabular} & $76.2 \%$ \\
\hline Thick walled gall bladder & 16 & $76.2 \%$ \\
\hline Multiple calculi & 3 & $14.3 \%$ \\
\hline Pericholecystic collection & 3 & $14.3 \%$ \\
\hline $\begin{array}{l}\text { Dilated CBD and IHBR with } \\
\text { choledocholithiasis }\end{array}$ & 3 & $14.3 \%$ \\
\hline \multicolumn{3}{|c|}{ Table 2. Investigations } \\
\hline
\end{tabular}

Preoperatively, 3 patients underwent ERCP along with CBD clearance for choledocholithiasis. One out of these required $\mathrm{CBD}$ stenting too. The various indications for Laparoscopic Subtotal Cholecystectomy are listed in Table 3.

\begin{tabular}{|c|c|c|}
\hline Indication & No. of Patients & Percentage \\
\hline $\begin{array}{c}\text { Severe fibrosis at Calot's } \\
\text { triangle }\end{array}$ & 9 & $42.9 \%$ \\
\hline Empyema gall bladder & 6 & $28.6 \%$ \\
\hline Mirizzi syndrome & 4 & $19.0 \%$ \\
\hline Gangrenous gall bladder & 2 & $9.5 \%$ \\
\hline \multicolumn{2}{|c|}{$\begin{array}{c}\text { Table 3. Indications for Laparoscopic Subtotal } \\
\text { Cholecystectomy }\end{array}$} \\
\hline
\end{tabular}

The shortest operative time was 60 mins in $1 / 21$ patients, while $3 / 21$ patients had total operative time ranging between $60-120$ mins and for the rest 17 patients it took more than 120 mins. The mean operative time of patients was $165.71 \pm 52.57$ mins. Intraoperative and post-operative encountered complications are cited in Table 4 and 5 respectively.

\begin{tabular}{|c|c|c|}
\hline Intraoperative Complications & $\begin{array}{c}\text { No. of } \\
\text { Patients }\end{array}$ & $\mathbf{\%}$ \\
\hline Adhesions with omentum and gall bladder & 12 & $57.1 \%$ \\
\hline Bile and stone spillage & 9 & $42.9 \%$ \\
\hline Bile spillage & 6 & $28.6 \%$ \\
\hline $\begin{array}{c}\text { Adhesions with omentum, bowel and gall } \\
\text { bladder }\end{array}$ & 5 & $23.8 \%$ \\
\hline Bleeding & 4 & $19.0 \%$ \\
\hline Minimal adhesions & 4 & $19 \%$ \\
\hline Bile duct injury & 1 & $4.8 \%$ \\
\hline Table 4. Intraoperative Complication Distribution \\
\hline
\end{tabular}

\begin{tabular}{|c|c|c|}
\hline Post-Operative Complication & No. of Patients & Percentage \\
\hline Bile leakage & 3 & $145.3 \%$ \\
\hline Port site infection & 3 & $14.3 \%$ \\
\hline Haemorrhage & 1 & $4.8 \%$ \\
\hline Mortality & 1 & $4.8 \%$ \\
\hline Table 5. Post-Operative Complication Distribution \\
\hline
\end{tabular}

The post-operative hospital stay ranged from 4 to 7 days for 12 patients, while 8 patients stayed for more than 7 days. Only one patient had the shortest post-operative hospital stay of 3 days. The mean duration of post-operative hospital stay of patients was $7.24 \pm 5.51$ days.

In majority of the patients $(10 / 21)$, the drain was removed between $4-7$ days. $2 / 21$ patients had postoperative drain in situ for more than 7 days. In $9 / 21$ patients, the drain was kept in place for 1 - 3 days. The mean duration for the drain in situ of patients in the study was $5.33 \pm 4.73$ days.

On histopathological analysis 3/21 (14.3\%) patients had acute cholecystitis, $8 / 21$ (38.1\%) patients had acute on chronic cholecystitis and 10/21 (47.6\%) patients had chronic cholecystitis.

\section{DISCUSSION}

The total number of laparoscopic cholecystectomies done during the total duration of the study was 1,926. The overall incidence of laparoscopic subtotal cholecystectomy in our study was $1.1 \%$, which was similar to the incidence reported by Philips et al[9] (1.4\%). A higher incidence of 3.33\%, 3.39\%, $3.1 \%$ and $4.8 \%$ was reported by Chowbey et al,[10] Elsebae et al,[11] Sinha et al[12] and $\mathrm{Wu}$ Ji et al,[13] respectively. While studies conducted by Mishra et al,[14] Nakajima et al[15] and Beldi et al[3] observed even a much higher incidence of $7.1 \%$, $10.2 \%$ and $13.3 \%$ respectively. This may be due to the fact that median age and American Society of Anesthesiologists (ASA) classification was higher for the patients in these studies, possibly representing severe disease. Other possible explanations for such big discrepancy may be attributable to skills of operating surgeon, experience with difficult gallbladder and willingness to convert to an open procedure.

In our study, the male: female ratio was almost equivalent. Philips et al[9] and Mishra et al[14] also reported that sex of the patient did not have any significant effect on the rate of laparoscopic subtotal cholecystectomy. Ebied et al,[16] Chowbey et al[10] and Sinha et al[12] reported a higher rate among males, while Memon et al[17] observed higher rates among females.

Various studies have observed old age as an independent risk factor for laparoscopic subtotal cholecystectomy. Almost similar results were observed in our study. The mean age in our study was $54.86 \pm 11.150$ years. The explanation for this may lie in the increase in severity of the disease with progression in age. Extensive fibrosis and recurrent inflammation may lead to frozen Calot's triangle leading to difficulty in dissection and identification of structures.

In present study, the associated percentage of comorbidities was similar to as observed by Chowbey et al.[10] Problems were encountered while operating in $3(14.3 \%)$ patients having chronic liver disease with portal hypertension (CLD-PHTN). Elsebae et al[11] and Wu Ji et al[13] also faced the similar situation in $3 / 18$ and $18 / 168$ patients respectively. The major problems encountered during the procedure were adhesions with increased neovascularity, maintaining of traction of liver, large venous collaterals in the liver hilum or around the gallbladder and bleeding, especially when dissecting the gallbladder from the liver bed. We resorted to minimum adhesiolysis using Harmonic scalpel if required. Traction of liver and a reasonable exposure was obtained by lifting the body of the gallbladder instead of the 
fundus. The posterior wall of the gallbladder was left intact with the liver and the mucosal ablation was done by electrocautery probe. In one patient bleeding was present from venous collaterals, for which clip was applied for haemostasis.

Our study observed gallbladder wall thickness and presence of multiple calculi as risk factor for a laparoscopic subtotal cholecystectomy as seen in the study done by Shin et al.[18] This was also in concordance with the study conducted by Randhawa and Pujahari ${ }^{[19]}$ and Lipman et al,[20] predicting the difficulty of laparoscopic cholecystectomy and conversion.

$6(28.6 \%)$ patients had elevated alkaline phosphatase levels and $3(14.3 \%)$ out of these had choledocholithiasis associated with common bile duct and intrahepatic biliary radical dilatation on ultrasonography, for which they underwent preoperative ERCP and CBD clearance and a CBD stent was placed in one patient. PK Chowbey et al[10] $(8.9 \%)$ and Michalowski et al[21] (13.7\%) reported similar observation in their study.

The indications for laparoscopic subtotal cholecystectomy in our study were similar to that observed by Memon et al[17] and Mishra et al[14] with majority of patient having chronic cholecystitis with severe fibrosis. In cases of empyema and gangrenous gallbladder, we proceeded with a suction cannula (hydrodissection technique) in order to open up planes which were then further dissected using a grasper and scissors with electrocautery. The dissection was limited to the neck of the gallbladder. The spilt stones were usually a problem in handling such gallbladders. A sterile Endobag was used to remove the specimen and the stones together. After removal of the specimen, the port tract was irrigated thoroughly. In case of contracted and fibrosed gallbladder which was densely covered with adhesions, the anatomical identification of structures and fundus grasping was difficult. The cystic stump was usually thick walled and was difficult to occlude, which was managed by different techniques. 1/0 PDS Endoloop knot was used in 12 patients, intracorporeal single layer suturing with $2 / 0$ vicryl was used in 6 patients and ligation of neck of gallbladder using $1 / 0$ silk suture in 3 patients. It is always a challenge to operate in the face of adhesions that could arise due to severe inflammatory conditions of gallbladder and as a result of any previous surgery. The conversion rates to the tune of $25 \%$ have been reported in patients with extensive upper abdomen adhesions. ${ }^{[20]}$ Complete lysis of all the adhesions was not done, but only the obstructing adhesions were lysed to clear the path. Careful sharp dissection and control of diffuse oozes were done with mild electrocautery.

Spillage of the gallbladder content was a common problem, which occurred frequently while performing this operative technique. Suction and irrigation of the opened gall bladder was promptly done in order to avoid any further contamination, stones present were removed in a sterile plastic Endobag along with the specimen. Intraoperative haemorrhage was managed by bipolar electrocoagulation when bleed was present from the liver bed as seen in 3 patients and clipping was done in one patient of portal hypertension when bleeding was present from venous collaterals. One patient had intraoperative bile duct injury (Strasberg type D), which was recognised intraoperatively, and primary repair was done laparoscopically using $4 / 0$ vicryl. Nakajima et al[15] reported single bile duct injury while performing laparoscopic subtotal cholecystectomy in 60 patients. While various studies conducted by Michalowski et al,[21] Ebied et al,[16] Wu Ji et al[13] and Mishra et al[14] did not observe any bile duct injury. Possible explanation for this can be attributable to laparoscopic experience and technical skills of surgeons. Also with the introduction of laparoscopic subtotal cholecystectomy it has helped surgeons prevent misidentification of bile duct, thereby reducing the incidence of biliary tract complication associated with laparoscopic cholecystectomy.

The discrepancy in the total operative time may be explained by the fact that the primary aim in our study was to perform a standard laparoscopic cholecystectomy and not laparoscopic subtotal cholecystectomy. The decision to perform laparoscopic subtotal cholecystectomy was made for only in the most severe cases.

Post-operative bile leak was seen in 3 out of 21 patients. 2 (9.5\%) out of these patients had persistent bile leak from the drain even after 10 th post-operative day, hence underwent post-operative endoscopic retrograde cholangiopancreatography and stenting and one patient was managed conservatively and leak resolved spontaneously after 6 days. The results of our study were similar to those reported by PK Chowbey et al,[10] K Michalowski et al[21] and Mishra et al[14] who performed Laparoscopic subtotal cholecystectomy with closure of the cystic stump. Beldi et al,[3] Philips et al[9] and Memon et al[17] performed such surgeries without cystic duct closure. It was seen that postoperative bile leak was more in cases where the cystic stump or remnant gallbladder was not closed in order to prevent bile duct injury. Post-operative haemorrhage was seen in one patient. There was fresh blood in the drain about $100 \mathrm{~mL} / 24 \mathrm{hrs}$ which stopped spontaneously on $3 \mathrm{rd}$ postoperative day. Epigastric port site infection was managed by antibiotics and aseptic dressings. One mortality was observed in our study. It involved an elderly male patient with chronic liver disease with portal hypertension with partial gangrene of the gallbladder with pericholecystic fluid, who developed acute respiratory distress syndrome with decompensated chronic liver disease. This death was not directly attributable to laparoscopic subtotal cholecystectomy.

Total hospital stay observed in our study was similar to what was reported by Michalowski et al[21] and Nakajima et al.[15] The longer duration of hospital may be explained by the extended hospitalisation required to treat the minor complications that occurred. The mean duration for the placement of the drain was $5.33 \pm 4.73$ days. Dhannur et al[22] observed and reported mean duration of drain placement of 3.5 days. Gallbladder cancer is reportedly found unexpectedly in $0.2-0.8 \%$ of patients undergoing laparoscopic cholecystectomy.[23] If the gallbladder wall is cut open in patients with gallbladder cancer, abdominal dissemination and remnant tumours are always observed. In our study, no cases of unexpected gallbladder cancer were identified intraoperatively, and histopathological analysis also did not find any gallbladder cancer. No cases of CBD injury was observed.

\section{CONCLUSION}

Our data suggested that laparoscopic subtotal cholecystectomy reduces the risk of bile duct injury in the 
most difficult cases while maintaining the other benefits of a laparoscopic approach, namely shorter hospital stay, no wound infection, no biliary injury and avoiding conversion to open cholecystectomy in patients with an obscured Calot's anatomy. However, the risk of stump cholecystitis and recurrence of gallstones in remnant gallbladder cannot be completely denied. Further prospective studies using a standardised predictive scale of procedure, difficulty would be helpful in clarifying the use of laparoscopic subtotal cholecystectomy. We do not advocate the use of laparoscopic subtotal cholecystectomy as a routine procedure or consider it to be a substitute for laparoscopic cholecystectomy, but we have demonstrated that laparoscopic subtotal cholecystectomy is a viable technique that may be a safe alternative to open subtotal cholecystectomy in patients with various forms of complicated cholecystitis.

\section{ACKNOWLEDGEMENTS}

The authors especially thank all the medical and non-medical staffs of the department and the hospital for their sincere work and cordial cooperation with this project.

\section{REFERENCES}

[1] Reynolds W Jr. The first laparoscopic cholecystectomy. Journal of the Society of Laparoendoscopic Surgeons 2001;5(1):89-94.

[2] Shikata S, Noguchi Y, Fukui T. Early versus delayed cholecystectomy for acute cholecystitis: a metaanalysis of randomized controlled trials. Surg Today 2005;35(7):553-60.

[3] Beldi G, Glattli A. Laparoscopic subtotal cholecystectomy for severe cholecystitis. Surg Endosc 2003;17(9):1437-9.

[4] Kuwabara J, Watanabe Y, Kameoka K, et al. Usefulness of laparoscopic subtotal cholecystectomy with operative cholangiography for severe cholecystitis. Surg Today 2014;44(3):462-5.

[5] Lawes D, Motson RW. Anatomical orientation and cross-checking: the key to safer laparoscopic cholecystectomy (Br J Surg 2005;92:663-4). Br J Surg 2005;92(11):1454-5.

[6] Lee J, Miller P, Kermani R, et al. Gallbladder damage control: compromised procedure for compromised patients. Surg Endosc 2012;26(10):2779-83.

[7] Eikermann M, Siegel R, Broeders I, et al. Prevention and treatment of bile duct injuries during laparoscopic cholecystectomy: the clinical practice guidelines of the European Association for Endoscopic Surgery (EAES). Surg Endosc 2012;26(11):3003-39.

[8] Zucker KA, Bailey RW, Flowers J. Laparoscopic management of acute and chronic cholecystitis. Surg Clin North Am 1992;72(5):1045-67.

[9] Philips JA, Lawes DA, Cook AJ, et al. The use of laparoscopic subtotal cholecystectomy for complicated cholelithiasis. Surg Endosc 2008;22(7):1697-700.
[10] Chowbey PK, Sharma A, Khullar R, et al. Laparoscopic subtotal cholecystectomy: a review of 56 procedures. J Laparoendosc Adv Surg Tech A 2000;10(1):31-4.

[11] Elsebae MMA, Nasr MMA, Ezzat H, et al. Laparoscopic approach for technically difficult gall bladder stone disease: the role of laparoscopic subtotal cholecystectomy. Kasr El Aini Journal of Surgery 2006;7:67-74.

[12] Sinha I, Smith ML, Safranek P, et al. Laparoscopic subtotal cholecystectomy without cystic duct ligation. British Journal of Surgery 2007;94(12):1527-9.

[13] Ji W, Li LT, Li JS. Role of laparoscopic subtotal cholecystectomy in the treatment of complicated cholecystitis. Hepatobiliary Pancreat Dis Int 2006;5(4):584-9.

[14] Mishra A, Mohanty SK, Sahoo SP, et al. Evaluation of usefulness of laparoscopic subtotal cholecystectomy in complicated cholecystitis. International Medical Journal 2015;2:342-5.

[15] Nakajima J, Sasaki A, Obuchi T, et al. Laparoscopic subtotal cholecystectomy for severe cholecystitis. Surg Today 2009;39(10):870-5.

[16] Ebied EF, Ebied H. Subtotal cholecystectomy in difficult laparoscopic cholecystectomies: is it safe? The Egyptian Journal of Surgery 2015;34(2):90-3.

[17] Memon MR, Bozdar AG, Mirani SH, et al. Laparoscopic subtotal cholecystectomy without cystic duct clipping. Medical Channel 2012;19:103-6.

[18] Shin M, Choi N, Yoo Y, et al. Clinical outcomes of subtotal cholecystectomy performed for difficult cholesystectomy. Ann Surg Treat Res 2016;91(5):22632.

[19] Randhawa JS, Pujahari AK. Preoperative prediction of difficult lap chole: a scoring method. Indian J Surg 2009;71(4):198-201.

[20] Lipman JM, Claridge JA, Haridas M, et al. Preoperative findings predict conversion from laparoscopic to open cholecystectomy. Surgery 2007;142(4):556-65.

[21] Michalowski K, Bornman PC, Krige JE, et al. Laparoscopic subtotal cholecystectomy in patients with complicated acute cholecystitis or fibrosis. British Journal of Surgery 1998;85(7):904-6.

[22] Dhannur PK, Prasad K, Prasad G. Laparoscopic subtotal cholecystectomy for complicated gall bladder surgeries: experience at our setup. Int J Med Res Health Sci 2016;5:13-6.

[23] Yamamoto H, Hayakawa N, Kitagawa Y, et al. Unsuspected gallbladder carcinoma after laparoscopic cholecystectomy. J Hepatobillary Pancreat Surg 2005;12(5):391-8. 